R. Martin FRCPC, L. Beauregard MD, Y. Lamarche FRCPC, J.P. Tétrault FRCPC

\title{
Comparison of lidocaine hydrocarbonate, lido- caine hydrochloride and mepivacaine in the axillary block
}

Axillary block was performed on 60 patients undergoing various types of surgical procedures on the upper limb. The patients were divided randomly into three equal groups of 20 and recelved lidocaine hydrocarbonate $1 \%$ or lidocaine hydrochloride $1 \%$ or mepivacaine $1 \%$, each solution containing epinephrine 1/400,000. A double-blind design was used. Lidocaine hydrocarbonate and lidocaine hydrochloride were both found to have a shorter latency of analgesia than mepivacaine. Duration of analgesia, quality of the sensory and motor block were not found 10 be statistically different between the three groups.

Lidocaine hydrocarbonate has been used for many years in Canada, but there is still controversy concerning its alleged superiority over the hydrochloride solutions in epidural anaesthesia. ${ }^{1-5}$ However, its effectiveness in brachial plexus block with the supraclavicular and interscalcne approaches has been reported gencrally to be supcrior to the lidocaine hydrochloride solutions. ${ }^{6-9}$

The present study was undertaken to compare the efficacy of lidocaine hydrocarbonate to lidocaine hydrochloride and mepivacaine hydrochloride when used for axillary blocks.

\section{Methods}

Sixty patients, 14 of whom had chronic renal failure, were studied in a double-blind manner, after they gave their informed consent. They were randomly divided into three

\section{Key words}

ANAESTHETIC TECHNIQUES, REGIONAL: axillary block; ANAESTHETICS, LOCAL: lidocaine hydrocarbonate, lidocaine hydrochloride, mepivacaine.

From the Department of Anaesthesia, Centre Hospitalier Universitaire de Sherbrooke, Sherbrooke, Québec.

Address correspondence to: Dr. R. Martin, Department of Anaesthesia, Centre Hospitalier Universitaire de Sherbrooke, 3001, 12th Avenue North, Fleurimont, Que., JIH 5N4. groups of 20 patients each, according to the local anaesthetic solution to be used. Group 1 received lidocaine hydrochloride $1 \%$ with epinephrine $1 / 400,000$, Group 2, lidocaine hydrocarbonate $1 \%$ with epinephrine $1 / 400,000$ and Group 3, mepivacaine hydrochloride $1 \%$ with epinephrine $1 / 400,000$. The three solutions were prepared by diluting $2 \%$ solutions, without preservatives, with $0.9 \mathrm{NaCl}$, and the epinephrine was then added.

The axillary block was performed with a standardized technique using a nerve stimulator ${ }^{10}$ by which the median, cubital, radial and musculo-cutaneous nerves were isolated according to the elicited movements. A current of 0.5 ma was used through a 22 -gaugc insulated pinpoint needle. A total dose of $25 \mathrm{ml} \cdot \mathrm{m}^{-2}$ of body surface was injected in four fractions, 75 per cent of the total dose being injected in equal parts on the two principal nerve trunks innervating the surgical field and the remaining 25 per cent being injected in equal parts on the two other nerves.

After completion of the infiltration of the first nerve the latency of analgesia was evaluated every minute at the surgical site, using a pin-prick method with a Wartenberg pinwheel. The duration of analgesia was taken to be the differenec between the time of complete analgesia at the surgical site and the time of first sensation of pain at that site during or after surgery. The quality of analgesia was defined as complete, partial or inadequate; complete meaning no discomfort at all during surgery, partial meaning some minor discomfort treated with 50 to $100 \mu \mathrm{g}$ of fentanyl or local infiltration and inadequate meaning a need to repeat the block or administer a general anaesthetic.

Each patient received $2.5-5 \mathrm{mg}$ of diazepam IV before the performance of the block. The motor block was evaluated after establishment of the sensory block at the site of surgery and was arbitrarily defined as being 0,30 , 60 or 100 per cent with 100 per cent indicating complete paralysis of the blocked limbs; 60 per cent loss of extension or flexion of the arm but possible movement of the hands; 30 per cent the ability to perform extension and flexion of the arm against gravity but not against resis- 


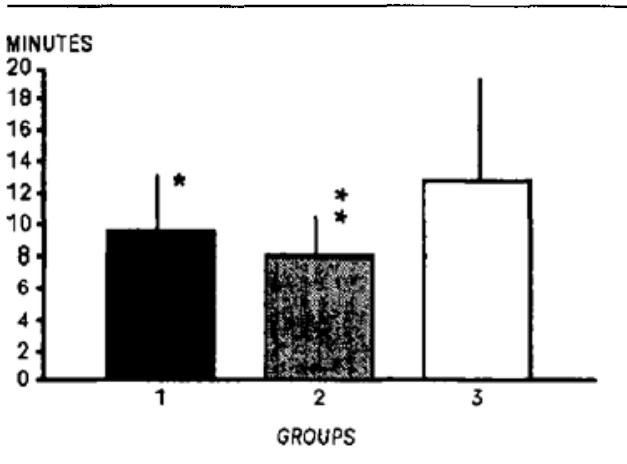

FIGURE 1 Latency of analgesia in minutes \pm SD to pin-prick for the first nerve injected. Group $1=$ lidoeaine $\mathrm{HCl}+\mathrm{E}$; Group $2=$ lidocaine $\mathrm{CO}_{2}+\mathrm{E}$; Group $3=$ mepivacaine $+\mathrm{E}$. ${ }^{*} \mathrm{p}<0.05$ : GI rs G3. **p $<0.005:$ G2 vs G3.

tance and 0 per cent meaning free movement against gravity and a small resistance.

The results werc analysed as follows: for parametric results, an analysis of variance was used, and a t test with Bonferoni correction for two by two comparisons. For nonparametric results, Kruskal-Wallis and Mann-Whitney $\mathrm{U}$ tests were used. The significance level was fixed at $p<0.05$.

\section{Results}

The three patient groups were not different with respect to age, the type of surgery (bone or soft tissues), site of surgery (hand, wrist, forearm or elbow) and use or absence of toumiquet. The mean age was 46 years for all patients. The 14 patients with renal failure were uniformly distributed into the three groups. The total dose of local anaesthetic injected (mean $=42 \mathrm{ml}$ ) was not different among the groups.

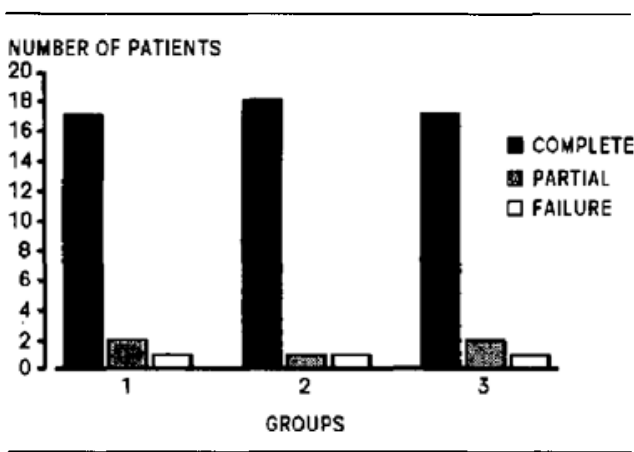

FIGURE 2 Quality of analgesia. Group $1=$ lidocaine $\mathrm{HCl}+\mathrm{E}_{\text {i }}$ Group $2=$ lidocaine $\mathrm{CO}_{2}+\mathbf{E}$; Group $3=$ mepivacaine $+\mathbf{E}$.

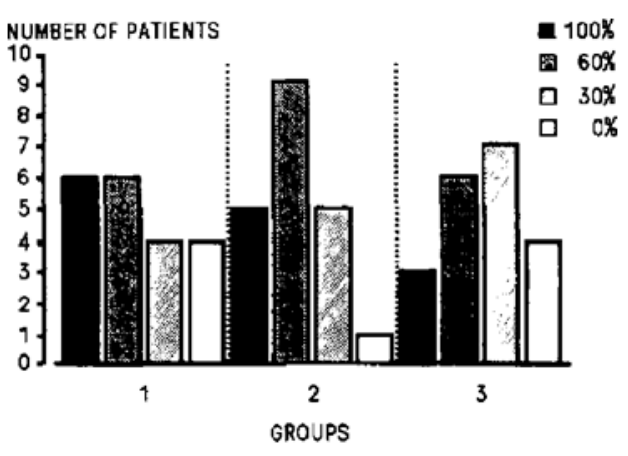

FIGURE 3 Quality of motor block. Group 1 = lidocaine $\mathrm{HCl}+\mathrm{E}$; Group $2=$ lidocaine $\mathrm{CO}_{2}+\mathrm{E}$; Group $3=$ mepivacaine $+\mathrm{E}$.

Latency for pin-prick analgesia was shortest with lidocaine hydrocarbonate and lidocaine hydrochloride (Figure 1), and this difference was statistically significant when compared to the latency with mepivacaine.

The quality of analgesia (Figure 2) and quality of motor block (Figure 3) and the duration of analgesia (Figure 4) were not significantly different among the three groups.

\section{Diseussion}

This study of lidocaine hydrocarbonate in axillary block did not find that this solution was statistically different from lidocaine hydrochloride in terms of rapidity of onset and motor block. With a technique of axillary block which selectively localizes the nerves, as performed here, the quality of sensory block was not found superior. However, diffusion of the local anaesthetic likely plays a larger part in plexus blocks where only one injection is performed and some diffusion is needed to anaesthetize the

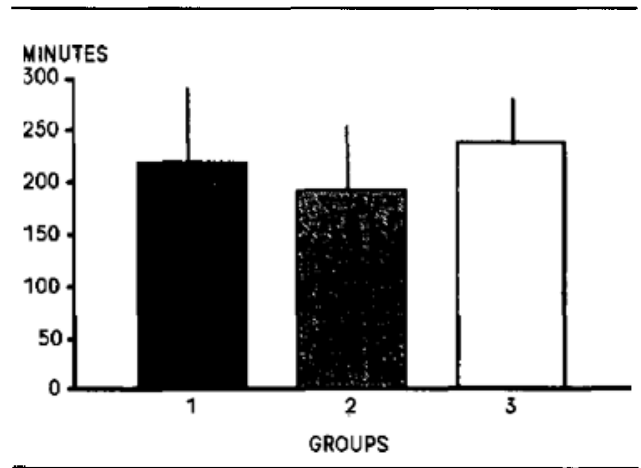

FIGURE 4 Duration of analges $a$ in minutes \pm SD. Group $1=$ lidocaine $\mathrm{HCl}+\mathrm{E} 1 / 400,000 ;$ Group 2 = lidocaine $\mathrm{CO}_{2}+\mathrm{E} 1 / 400,000$; Group $3=$ mepivacaine + E $1 / 400,000$. 
whole plexus. This diffusion effect is evident in the interscalene approach use by Sukhani et al..$^{9}$ where lidocaine hydrochloride was found to anaesthetize the entire hand in 53 per cent of patients and lidocaine hydrocarbonate in 87 per cent of patients. The effect of improved diffusion is less apparent with our technique where we measure the latency for one specific nerve. The rate of diffusion and the time it takes for a solution injected on a nerve to produce anaesthesia in the area innervated by that nerve, are two different concepts. A part of the controversy about carbonated lidocainc in epidural anaesthesia concerns that problem. ${ }^{11}$ In fact, the studies that looked at the time for analgesia to develop in different dermatomes (latency profile) showed a marked advantage of the carbonated solutions over the hydro. chloride solutions in epidural and in plexus block anaesthesia. ${ }^{5}{ }^{8}$ However, the studies that determine the time to reach the highest dermatome level with epidural anaesthesia ${ }^{1-4}$ or the time to achieve complete analgesia when injections are made at a specific nerve, as in the present study, show a less marked advantage for carbonated lidocaine.

In the present study the $1 \%$ solutions were prepared from $2 \%$ solutions by dilution with $0.9 \mathrm{NaCl}$ and the epinephrine was then added, just before the injection. This may be detrimental to the hydrocarbonated solutions because of dilution of the $\mathrm{pCO}_{2}{ }^{12}$ The $\mathrm{pCO}_{2}$ of the solution was $88.9 \mathrm{kPa}(669 \mathrm{mmHg})$ before dilution and $40.9 \mathrm{kPa}(308 \mathrm{mmHg})$ after dilution.

Considering that $1 \%$ or $1 \%$ equivalent solutions are suggested for plexus anaesthesia, ${ }^{13}$ the $1 \%$ equivalent of lidocaine hydrocarbonated preparations could be more convenient than $2 \%$ solutions in plexus or peripheral nerve blocks.

We conclude that in the context of this study carbonated lidocaine, although faster in onset than mepivacaine, was not significantly different from lidocaine hydrochloride in onset time. Carbonated lidocaine, lidocaine hydrochloride and mepivacaine hydrochloride were not different with respect to quality of analgesia, quality of motor block and duration of analgesia.

\section{References}

1 Martin R, Lamarche Y, Terreault L. Comparison of the clinical effectivenes of lidocaine hydrocarbonate and lidocaine hydrochloride. Can Anaesth Soc J 1981; 28: $217-23$.

2 Morison DH. A double-blind comparison of carbonate lidocaine and lidacaine hydrochloride in epidural anaesthesia. Can Anaesth Soc J 1981; 28: 387-9

3 Hemmings $C T$, Weeks $S K$, 5 mith $J B$. Epidural anesthesia for Caesarean section; lidocaine- $\mathrm{HCl}$ versus lidocaine-

$\mathrm{CO}_{2}$. Can Anaesth Soc J 1983; 30: S84-S85.
4 Cole CP, MCMorland GH, Axelson JE, Jenkins LC. Epidural blockade for Caesarean section comparing lidocaine hydrocarbonate and lidocaine hydrochloride. Anesthesiolo gy $1985 ; 62: 348-50$

5 Nickel PM, Bromage PR, Sherrill DL. Comparison of hydrochloride and carbonated salts of lidocaine for epidural analgesia. Regional Anesthesia 1986; 11:62-7.

6 Schulte-Steinberg O, Hartmuth J, Schult $L$. Carbon dioxide salts of lidocaine in brachial plexus block. Anaesthesia 1970; 25: 191-7.

7 Bromage PR, Gertel $M$. Improved brachial plexus blockade with hydrochloride and carbonated lidocaine. Anesthesiology 1972; 36: 479-87.

8 Sukhani $R$, Yanez-Segura VM, Winnie AP. Comparative clinical pharmacokinctics of the hydrocarbonate and hydrochloride salts of lidocaine in plexus blocks. Anesthesiology 1985; 63: A209

9 Sukhani $R$, Schlake PT, Winnie AP. Comparison of the carbonate and hydrochloride salts of lidocaine in interscalene brachial plexus blocks. Anesthesiology 1986; 65: Al86.

10 Cuillerier DJ, Martin R, Léna P. Lamarche Y, Black R Axillary block: a method to improve its success rate. Can Anaesth Soc J 1985; 32: 771 .

11 Bromage PR, Nickel PM, Winnie AP, Sukhani R. Local anesthetics: the carbonation controversy - a scientific exhibit presented at the 60th Congress of the International Anesthesia Research Society, Las Vegas, March 1986 (personal communication). Dr. Philip R. Bromage and Dr. Peter M. Nickel: University of Colorado Health Sciences Center, Denver, Colorado, Dr. Alan P. Winnie and Dr. Rodha Sukhani: University of Illinois Medical Center, Chicago, Illinois.

12 Soderman M, Duke PC. Stability of carbonate lidocaine. Can Anaesth Soc J 1983; 30: S7I.

13 Cousins MJ, Bridenbaugh PO. Neural blockade. Philadelphia: J.B. Lippincott Company, 1980, p. 147.

\section{Résumé}

Soixante patients soumis a différentes chirurgies du membre supérieur sous bloc axillaire ont été étudiés. Ils ont été divisés au hasard en trois troupes de 20 patients selon qu'ils reçurent comme anesthêsique local de la lidocaine hyirachlorée, de la Irdocaïne hydrochlorée, de la lidocaine carbonatée ou de la mépivacaine, chaque solution contenant $1 \%$ dis produit actif avec épinéphrine $1 / 400,000$. L'étude était à double insu. La latence d'analgésie a été plus courte pour la lidocaine carboratéc et la lidocaine hydrochlorée que pour la mépivacä̈ne. La durée d'analgésie, la qualité des blocs sensitif et moseur n'ont cependant pas été trouvés significativement différents dans les trois groupes. 